\title{
Thromboxane B2 Measurement
}

National Cancer Institute

\section{Source}

National Cancer Institute. Thromboxane B2 Measurement. NCI Thesaurus. Code C103445.

The determination of the amount of the thromboxane B2 in a sample. 